\title{
Validation and Application of a Methodology for Quantifying Levels of Parabens in Sports Supplements from Brazil Using Liquid Chromatography-Mass Spectrometry
}

\author{
Bruno A. Rocha, ${ }^{\circledR a}$ Cibele A. Cesila, ${ }^{a}$ Airton C. Martins, ${ }^{\circledR b}$ Marília C. O. Souza ${ }^{\circledR a}$ and \\ Fernando Barbosa Jr. ${ }^{\circledR *, a}$
}

\author{
${ }^{a}$ Departamento de Análises Clínicas, Toxicológicas e Bromatológicas, \\ Faculdade de Ciências Farmacêuticas de Ribeirão Preto, Universidade de São Paulo, \\ Avenida do Café $s / n^{\circ}$, 14040-903 Ribeirão Preto-SP, Brazil
}

${ }^{b}$ Department of Molecular Pharmacology, Albert Einstein College of Medicine, 1300 Morris Park Avenue, 10461 Bronx, NY, USA

\begin{abstract}
Although parabens have been reported to be used as antimicrobial preservatives in personal care products, pharmaceuticals, and foodstuffs, little is known about the occurrence of these compounds in sports supplements. In this study, a simple, fast and sensitive liquid chromatography tandem mass spectrometry method for simultaneous determination of five commonly used parabens, methyl-, ethyl-, propyl-, butyl-, and benzylparaben in sports supplements was established. The analytical method was validated with the values of parameters being acceptable. The method proved reliable, accurate, and sensitive and was successfully applied for the quantitation of parabens in 85 sports supplements samples. Almost all sports supplements contained at least one of the parabens analyzed, and the total concentrations of five parabens ranged from below the limit of quantification to $145 \mu \mathrm{g} \mathrm{g}^{-1}$, with a median value of $0.171 \mu \mathrm{g} \mathrm{g}^{-1}$. Ethylparaben and methylparaben were the most frequent paraben analogs found in samples (detection rate $>60 \%$ ). Propylparaben, butylparaben and benzylparaben are forbidden in food samples, their detection rates were 49.4, 21.2 and 4.7\%, respectively. Therefore, our study suggests that Brazilian population may be exposed to estrogenic not allowed parabens and their harmful effects through the intake of sports food supplements.
\end{abstract}

Keywords: endocrine-disrupting chemicals, human exposure, LC-MS/MS, parabens, sports supplements

\section{Introduction}

Endocrine-disrupting compounds (EDCs) are naturally or synthetically occurring substances that interfere with the synthesis, secretion, transport, action, or excretion of natural hormones in the body by altering homeostatic control, reproduction, or the developmental process. ${ }^{1-4}$ Contaminants classified as EDCs are highly heterogeneous and include products of anthropogenic origin such as organochlorine pesticides, vinclozolin (fungicide), dioxins and polychlorinated biphenyls (industrial byproducts), polybrominated diphenyl ethers (flame retardants), phthalates (plasticizers), bisphenols (plasticizers) and parabens (preservatives) $)^{5-7}$ EDCs may cause adverse effects at low concentrations and can be harmful to human

*e-mail: fbarbosa@fcfrp.usp.br

Editor handled this article: Eduardo Carasek and other animal health..$^{6-8}$ Therefore, source identification and exposure dose estimation are important for carrying out human and environmental risk assessment of the use of EDCs.

Parabens are a group of esters of $p$-hydroxybenzoic acid, and they act as antimicrobial agents, being largely used as preservatives in cosmetics, pharmaceuticals and foods. ${ }^{9-11}$ The antimicrobial activity of parabens increased with the increase of the ester grouping chain and they can be used individually or in combination with other preservatives. ${ }^{12-16}$ Parabens are commonly used due to their broad-spectrum antimicrobial activity against bacteria, yeasts and molds, are highly stable at $\mathrm{pH}$ and temperature variations, are water soluble, do not alter the consistency or color of products, are relatively safe to use and have low production costs. ${ }^{9-11,17}$ However, studies in vivo and in vitro have shown that parabens have the potential to disrupt endocrine function and that the estrogenic activity 
of these compounds increases with the length of the alkyl chain. ${ }^{9,13,18-22}$

The extensive use of parabens results in their omnipresence in the environment, and humans are exposed to parabens through a wide variety of sources via ingestion, inhalation, and dermal absorption..$^{7,10,11,17,23,24}$ Parabens have been reported in human urine, ${ }^{15,25-28}$ serum, ${ }^{29}$ breast tissues in some patients with breast cancer, ${ }^{19}$ breast milk, ${ }^{30}$ human semen ${ }^{31}$ and human brain. ${ }^{32}$ Due to the potential endocrine effect of parabens, the investigation of the sources of exposure has received attention currently and they have been detected in personal care, ${ }^{33-35}$ pharmaceuticals ${ }^{36,37}$ and food. ${ }^{7}$

Sports supplements are products with a nutritional or physiological effect, intended to supplement the normal diet and include vitamins, minerals, herbs, amino acids and enzymes. ${ }^{38,39}$ Sports supplements have been used by all age groups with aim of disease prevention, to compensate inadequate food intake, increasing physical performance and gaining muscle mass. ${ }^{40-42}$ In the United States, approximately half of the population uses 1 or more sports supplements ${ }^{40}$ and a study from European Union reported that more than one-third of the participants in United Kingdom, Denmark, Sweden and Norway had used supplements in in the last 24 hours. ${ }^{43}$ It is well documented that some commercially available sports supplements may exhibit quality deviations such as the presence of contaminants and misleading labels, ${ }^{44,45}$ as well as excessive levels of permitted substances. ${ }^{46}$ Therefore, evaluation of the presence of parabens in food supplements is extremely important for a risk assessment of human exposure to these compounds. Although the occurrence of estrogenic compounds in sports supplements has been reported, ${ }^{47,48}$ information on the presence of parabens in sports supplements is still scarce. Therefore, in this study, a method based on liquid chromatography coupled with triple quadrupole tandem mass spectrometry was established and validated for the determination of five commonly used parabens in sports supplements and further applied to 85 real samples collected from Brazil.

\section{Experimental}

\section{Chemical and reagents}

The analytical standards of parabens (methyl- (MeP), ethyl- (EtP), propyl- (PrP), butyl- (BuP), benzyl- (BzP), methyl-protocatechuic acid), parabens internal standard mix solution (methyl 4-hydroxybenzoate-ring- ${ }^{13} \mathrm{C}_{6}$, ethyl 4-hydroxybenzoate-ring- ${ }^{13} \mathrm{C}_{6}$, propyl 4-hydroxybenzoatering- ${ }^{13} \mathrm{C}_{6}$, butyl 4-hydroxybenzoate-ring- ${ }^{13} \mathrm{C}_{6}$ ), and methyl tert-butyl ether (MTBE) were purchased from Sigma-Aldrich $^{\circledR}$ (St. Louis, USA). High performance liquid chromatography (HPLC)-grade methanol was purchased from JT Baker ${ }^{\circledR}$ (Phillipsburg, USA). High purity water (resistivity $18.2 \mathrm{M} \Omega \mathrm{cm}$ ) used throughout the experiment was obtained using a Milli-Q water purification system ${ }^{\circledR}$ (Millipore RiOs-DITM, Bedford, USA). The individual stock solutions of each standard were prepared by dissolution in methanol and stored in amber glass vials at $-20{ }^{\circ} \mathrm{C}$. The calibration and working standard solutions were prepared daily from the stock solutions through serial dilution with methanol:water $(1: 1 \mathrm{v} / \mathrm{v})$ and stored in polypropylene tubes at $4{ }^{\circ} \mathrm{C}$ until analysis.

\section{Sample collection and preparation}

A total of 85 sports supplements (solid samples) were collected in Ribeirão Preto, Brazil, from January to December 2019. For this research, a small amount (around five grams) of the sports supplements were obtained from a voluntary donation. The selected samples included commonly used sports supplements such as creatine monohydrate, whey protein, and body-building tablets. Several ingredients were listed including proteins, carbohydrates, amino acids, vitamins, minerals, plant, and herbal extracts. The sample preparation and the analysis of five parabens were carried out following the method previously described elsewhere, ${ }^{36}$ with some modifications. Briefly, an amount of around $0.40 \mathrm{~g}$ of each sample was placed in a $15 \mathrm{~mL}$ polypropylene conical tube and spiked with the paraben internal standards (50 ng), then equilibrated for $30 \mathrm{~min}$ at room temperature. Then, the sample was shaken with $5 \mathrm{~mL}$ MTBE. The extraction procedure of parabens was performed by an orbital shaker for $60 \mathrm{~min}$. After centrifugation at $2500 \times \mathrm{g}$ for $10 \mathrm{~min}$, the supernatant was transferred to a clean $15 \mathrm{~mL}$ polypropylene tube. The same extraction procedure was repeated with an additional $5 \mathrm{~mL}$ MTBE, to increase analytes recovery. After that, the supernatants were combined and evaporated. The dried residues were reconstituted with $1000 \mu \mathrm{L}$ of the mixture of methanol:water $(1: 1 \mathrm{v} / \mathrm{v})$, vortexed for $10 \mathrm{~s}$, filtered and, then transferred into a vial. Thereafter, the sample was injected into the liquid chromatography electrospray ionization tandem mass spectrometer (LC/ESI-MS/MS).

\section{Instrumentation and sample analysis}

The instrumental analysis was performed with a Thermo Scientific ${ }^{\circledR}$ LC system equipped with a pump (Accela 600 pump) and an autosampler coupled with a 
triple quadrupole mass spectrometer (Thermo Scientific TSQ Quantum Access Max, Thermo Scientific ${ }^{\mathrm{TM}}$, San Jose, USA), operated in the electrospray negative ionization mode. The chromatographic separation was carried out on an Atlantis ${ }^{\circledR}$ T3 $\mathrm{C} 18$ column $(75 \mathrm{~mm} \times 2.1 \mathrm{~mm}$ internal diameter and $3.0 \mu \mathrm{m}$ particle size, Waters Milford, USA). An aliquot of $10 \mu \mathrm{L}$ was injected into the column, and the mobile phase was composed of methanol:water in gradient elution mode at a flow rate of $0.5 \mathrm{~mL} \mathrm{~min}^{-1}$. The gradient program starts at $25 \% \mathrm{MeOH}$, followed by a direct switch to $95 \% \mathrm{MeOH}$ in $6.5 \mathrm{~min}$, maintaining this percentage for $1.5 \mathrm{~min}(6.5-8 \mathrm{~min})$; and finally, to $25 \% \mathrm{MeOH}$ and held for 1.8 min before the next injection (total run time $10 \mathrm{~min}$ ). The column and sample tray temperature were kept at 40 and $15{ }^{\circ} \mathrm{C}$, respectively. The mass spectrometer conditions used in this study included capillary voltage kept at $-4000 \mathrm{~V}$ and capillary temperature of $220^{\circ} \mathrm{C}$. Nitrogen was used as a sheath gas and auxiliary gas at flow rates of 20 and 15 arbitrary units, respectively. The vaporizer temperature was set at $230^{\circ} \mathrm{C}$. The deprotonated molecule $[\mathrm{M}-\mathrm{H}]^{-}$was used as a precursor ion for all analytes in the mass spectrometry. Argon was used as a collision-induceddissociation (CID) gas at 1.9 mTorr. The data processing and the control of the instrument were performed using the Xcalibur software ${ }^{\circledast}$ version 2.0 (Thermo Fisher Scientific). To optimize the source working conditions and to carrying out the tandem mass spectrometry experiments, a stock standard solution of each compound at a concentration of $1 \mu \mathrm{g} \mathrm{mL}^{-1}$ was infused directly into the TSQ instrument. The infusion was realized using a syringe pump integrated into the TSQ instrument with a flow rate of $50 \mu \mathrm{L} \mathrm{min}{ }^{-1}$, and then the standard solution was to mixed the mobile phase $\left(450 \mu \mathrm{L} \mathrm{min}^{-1}, \mathrm{MeOH}: \mathrm{H}_{2} \mathrm{O}\right)$. The selective reaction monitoring (SRM) in negative mode was used for mass spectrometry analysis (Table 1). Figure 1 shows the resulting LC-MS/MS chromatograms recorded from pure standard solutions.

\section{Analytical figures of merit}

The analytical performance for the parabens determination was conducted in terms of selectivity, matrix effect, linearity, accuracy, and precision as well as sensitivity described as limit of detection (LOD) and limit of quantification (LOQ). The method selectivity was checked if whether there were any interference peaks at the expected retention windows as the targets compound by comparing the chromatograms obtained from analysis of blank samples with the spiked ones. To evaluate matrix effect, two types of calibration curves in blank matrix extract-purify solution and a mixture of $\mathrm{MeOH}: \mathrm{H}_{2} \mathrm{O}$ were prepared. A value close to $100 \%$ indicates no significant matrix effect, while values higher than $100 \%$ or lower than $100 \%$ indicate signal enhancement or suppression, respectively. The matrix effect was studied by comparison of the slopes of the calibration curves in solvent and in matrix and calculated as follows: matrix effect $(\mathrm{ME}(\%)=$ (slope of matrix - matched standard curves/slope of solvent standard curves) $\times 100 \%$ ). The LODs and LOQs were obtained according to signal-to-noise ratios $(\mathrm{S} / \mathrm{N}) \geq 3$ and $(\mathrm{S} / \mathrm{N}) \geq 10$, respectively. Quantification of analytes was performed using linear regression (linearity) generated from a ten-points calibration standard curve with concentrations from 1 to $100 \mathrm{ng} \mathrm{mL}^{-1}$. The isotopically labelled compounds were used as internal standards for quantification. The accuracy and precision were evaluated through intra- and inter-assay studies by recovery experiments and relative standard deviations (RSDs, \%) analysis of a pool of

Table 1. Selected reaction monitoring (SRM) transitions, the internal standard used, optimized collision energy (CE), tube lens, and retention times $\left(\mathrm{t}_{\mathrm{R}}\right)$ in the parabens analysis

\begin{tabular}{|c|c|c|c|c|c|}
\hline Compound & Precursor ion (Q1) & Quantification ion (Q3) & $\mathrm{CE} / \mathrm{eV}$ & Tube lens & $\mathrm{t}_{\mathrm{R}} / \min$ \\
\hline $\mathrm{MeP}$ & 151 & 92 & 22 & 105 & 2.5 \\
\hline${ }^{13} \mathrm{C}_{6}-\mathrm{MeP}$ & 157 & 98 & 24 & 40 & 2.5 \\
\hline EtP & 165 & 92 & 23 & 117 & 3.3 \\
\hline${ }^{13} \mathrm{C}_{6}$-EtP & 171 & 98 & 25 & 46 & 3.3 \\
\hline PrP & 179 & 92 & 25 & 103 & 4.1 \\
\hline${ }^{13} \mathrm{C}_{6}-\mathrm{PrP}$ & 185 & 98 & 36 & 50 & 4.1 \\
\hline $\mathrm{BuP}$ & 193 & 92 & 27 & 85 & 4.8 \\
\hline${ }^{13} \mathrm{C}_{6}-\mathrm{BuP}$ & 199 & 98 & 24 & 55 & 4.8 \\
\hline $\mathrm{BzP}^{\mathrm{a}}$ & 227 & 92 & 27 & 115 & 4.7 \\
\hline
\end{tabular}

${ }^{a 13} \mathrm{C}_{6}-\mathrm{BuP}$ was used as internal standard. MeP: methylparaben; ${ }^{13} \mathrm{C}_{6}-\mathrm{MeP}$ : methyl 4-hydroxybenzoate-ring- ${ }^{13} \mathrm{C}_{6}$; EtP: ethylparaben; ${ }^{13} \mathrm{C}_{6}-\mathrm{EtP}:$ ethyl 4-hydroxybenzoate-ring- ${ }^{13} \mathrm{C}_{6}$; PrP: propylparaben; ${ }^{13} \mathrm{C}_{6}$-PrP: propyl 4-hydroxybenzoate-ring- ${ }^{13} \mathrm{C}_{6}$; BuP: butylparaben; ${ }^{13} \mathrm{C}_{6}$ - $\mathrm{BuP}$ : butyl 4-hydroxybenzoatering- ${ }^{13} \mathrm{C}_{6} ; \mathrm{BzP}$ : benzylparaben. 


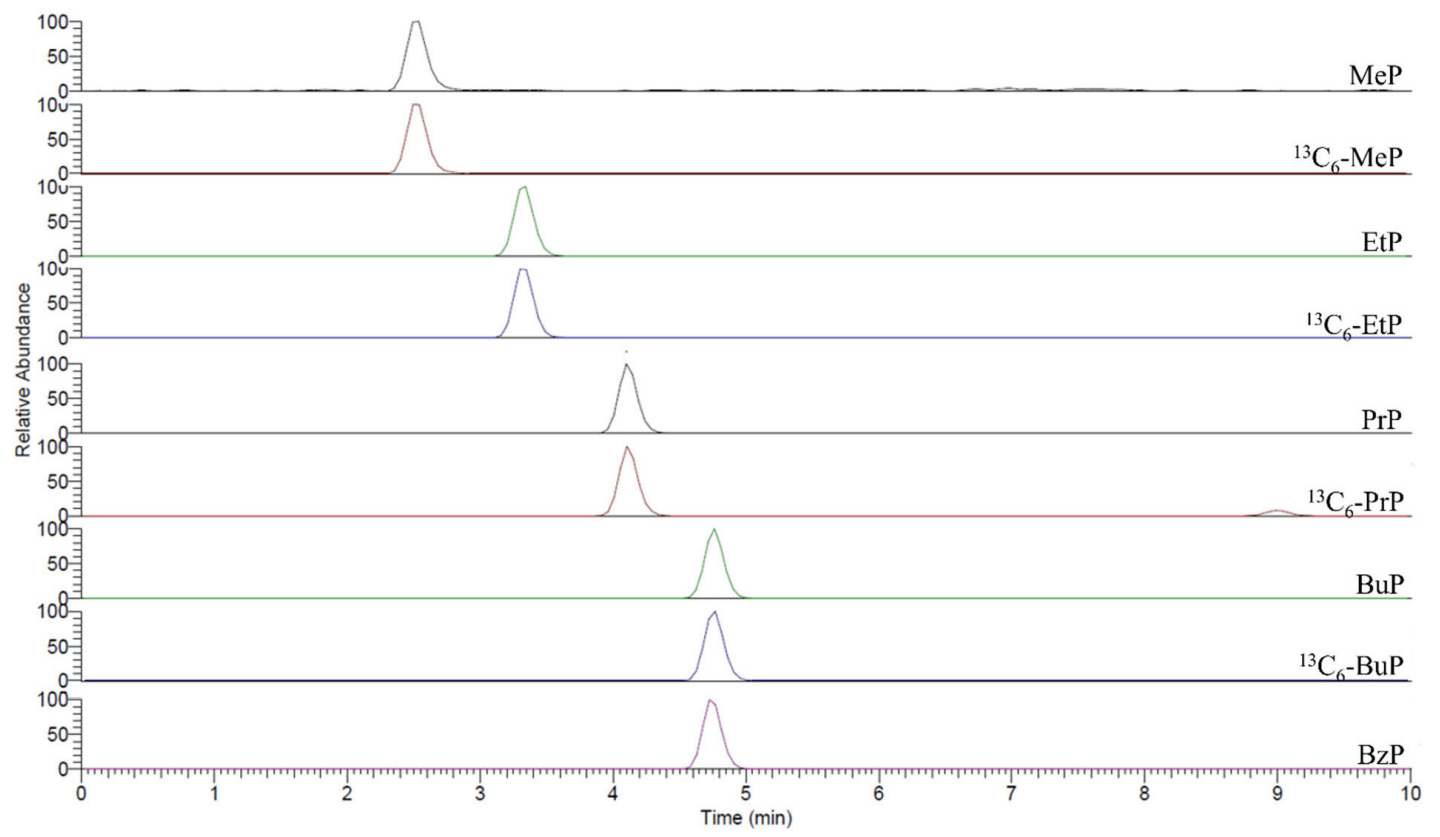

Figure 1. Extracted ion chromatograms showing peaks of studied parabens and internal standards $\left(10 \mathrm{ng} \mathrm{g}^{-1}\right)$ in matrix-matched standard working solutions containing all the compounds.

blank samples spiked at three concentrations $(1,50$, and $100 \mathrm{ng} \mathrm{g}^{-1}$ ), respectively.

\section{Results and Discussion}

\section{Analytical performance}

Selectivity was evaluated by analyzing ten blank samples which were spiked with internal standards and subjected to the whole analysis procedure to check if there were any detectable interference peaks in monitored time windows, which might lead to some false positive results. The MRM chromatograms showed good peak resolution of each paraben and an absence of peaks from the analysis of blank samples at the corresponding retention times of studied parabens. Therefore, these data confirm the selectivity of the proposed LC-MS/MS method for the determination of parabens in sports supplements.

Matrix effects can lead to enhanced or suppressed ionization of the target analytes when the electrospray ionization method is used to perform the analysis. ${ }^{49}$ This can affect the accuracy of quantification results and the reproducibility of the proposed method. The values of the matrix effect were shown in Table 2. As indicated by the values of matrix effect, no significant suppression or enhancement for parabens in sports supplements was observed. In this study, parabens internal standard mix solution (methyl 4-hydroxybenzoate-ring- ${ }^{13} \mathrm{C}_{6}$, ethyl 4-hydroxybenzoate-ring- ${ }^{13} \mathrm{C}_{6}$, propyl 4-hydroxybenzoatering- ${ }^{13} \mathrm{C}_{6}$, butyl 4-hydroxybenzoate-ring- ${ }^{13} \mathrm{C}_{6}$ ) were used for correcting sample preparation recovery and matrix effects influence.

In most validation guidelines linearity is defined as the ability of the analytical method to obtain results which are directly proportional to the concentration of analyte in the sample. ${ }^{50} \mathrm{~A}$ linear relationship is the simplest mathematical relationship with a constant accuracy over the complete range in contrast to quadratic fitting. Therefore, linear regression is the preferred mathematical method for calibration of analytical methods. ${ }^{51}$ In this study, the linearity was determined by building a ten-concentration analytical curve in the range of $1.0-100 \mathrm{ng} \mathrm{mL}^{-1}$ for each compound. The isotopically labelled compounds were used as internal standards to account for instrument variability and for quantification. Each signal intensity was plotted in a calibration graph corresponding to the average ratio of the analyte-to-internal standard peak areas obtained from three independent chromatographic runs. The obtained results are shown in Table 2 . The linearity of the calibration plots provided a correlation coefficient higher than 0.99 indicating a good linearity. Relative standard deviations at medium concentrations lower than $10 \%$ indicate satisfactory reproducibility of measurements within the linear dynamic ranges of the calibration curves. Residual errors were randomly distributed around zero, with the standardized residual values lower than 2 , thereby implying that no outliers were identified in the linear model. According to the lack of fit test, the calculated $F$-statistic was greater against the tabulated $F$ for a significance level $\alpha=0.05$. 
Table 2. Analytical figures of merit for the LC-MS/MS method for analysis of parabens in sports supplements

\begin{tabular}{lccccc}
\hline Paraben & ME / $\%$ & LOD / $\left(\mathrm{ng} \mathrm{mL}^{-1}\right)$ & LOQ / $\left.(\mathrm{ng} \mathrm{mL})^{-1}\right)$ & Linear equation & $\mathrm{r}$ \\
\hline MeP & 92 & 0.15 & 0.5 & $0.3423 x-0.0763$ & 0.9932 \\
EtP & 93 & 0.15 & 0.5 & $0.2820 x-0.0445$ & 0.9921 \\
PrP & 92 & 0.15 & 0.5 & $0.3765 x-0.0472$ & 0.9944 \\
BuP & 99 & 0.3 & 1.0 & $0.3374 x+0.0628$ & 0.9939 \\
BzP & 94 & 0.3 & 1.0 & $0.5795 x+0.1293$ & 0.9932 \\
\hline
\end{tabular}

ME: matrix effect; LOD: limit of detection; LOQ: limit of quantification; r: correlation coefficient; MeP: methylparaben; EtP: ethylparaben; PrP: propylparaben; BuP: butylparaben; BzP: benzylparaben.

In the present study, the LODs and LOQs were estimated from analysis of matrix-matched standards (pool of blank samples) as values at which the signal-to-noise ratios were 3 and 10 , respectively. The ratios of the analyte signal to the noise in chromatogram were determined with the XCalibur software. The obtained results are shown in Table 2 .

Precision characterizes the closeness of agreement between the measured values obtained by replicate measurements on the same or similar know samples under specified conditions, while the accuracy of a measurement result refers to the closeness of agreement between the measured value and the true value..$^{50}$ In this study, the accuracy and precision of the method were evaluated in terms of recoveries and relative standard deviation (RSD, \%) of the within- (five spiked blank pool samples for each concentration on the same day) and between-day (five spiked blank pool samples for each concentration for three consecutive days) tests, calculated by fortifying a pool of blank samples with target analytes at three different concentrations $\left(1.0,50\right.$, and $\left.100 \mathrm{ng} \mathrm{g}^{-1}\right)$. Samples were prepared and analyzed using the previously mentioned procedure. Table 3 provides information on the accuracy and precision of the proposed method. Blank measurements were made with a non-spiked pool of blank samples, which showed no evidence of the presence of the studied compounds. The average extraction recoveries found among tested spiking levels ranged from 90 to $109 \%$, confirming the accuracy of the method. Precision values $(\%$ RSD $<10)$ were satisfactory and met the acceptance criteria of the validation guidelines (RSD\% and relative error values lower than $15 \%$ ).

\section{Concentrations of parabens in sports supplements}

The concentrations and detection frequency of parabens in sports supplements are listed in Table 4. Almost all

Table 3. Accuracy and precision of the LC-MS/MS method for analysis of parabens in sports supplements

\begin{tabular}{|c|c|c|c|c|c|}
\hline \multirow{2}{*}{ Paraben $^{a}$} & \multirow{2}{*}{ Spiked / $\left(\right.$ ng g $\left.^{-1}\right)$} & \multicolumn{2}{|c|}{ Within-run } & \multicolumn{2}{|c|}{ Between-run $^{c}$} \\
\hline & & Accuracy / \% & Precision $(\mathrm{RSD})^{\mathrm{b}} / \%$ & Accuracy $/ \%$ & Precision (RSD) $)^{\mathrm{b}} / \%$ \\
\hline & 1.0 & 99 & 5 & 92 & 9 \\
\hline \multirow[t]{3}{*}{$\mathrm{MeP}$} & 50.0 & 95 & 6 & 90 & 8 \\
\hline & 100.0 & 106 & 2 & 96 & 9 \\
\hline & 1.0 & 102 & 5 & 100 & 5 \\
\hline \multirow[t]{3}{*}{ EtP } & 50.0 & 103 & 3 & 100 & 3 \\
\hline & 100.0 & 99 & 4 & 99 & 6 \\
\hline & 1.0 & 109 & 8 & 103 & 10 \\
\hline \multirow[t]{3}{*}{ PrP } & 50.0 & 99 & 4 & 110 & 9 \\
\hline & 100.0 & 95 & 0 & 106 & 5 \\
\hline & 1.0 & 94 & 6 & 106 & 6 \\
\hline \multirow[t]{3}{*}{$\mathrm{BuP}$} & 50.0 & 106 & 7 & 100 & 8 \\
\hline & 100.0 & 93 & 1 & 96 & 2 \\
\hline & 1.0 & 105 & 1 & 109 & 1 \\
\hline \multirow[t]{2}{*}{$\mathrm{BzP}$} & 50.0 & 94 & 2 & 102 & 9 \\
\hline & 100.0 & 105 & 6 & 100 & 6 \\
\hline
\end{tabular}

${ }^{a}$ Number of replicates $=3$; ${ }^{b}$ relative standard deviation; ${ }^{\text {cbased }}$ on three different consecutive days. MeP: methylparaben; EtP: ethylparaben; PrP: propylparaben; BuP: butylparaben; BzP: benzylparaben. 
Table 4. Concentration of parabens in sports supplements collected from Brazil

\begin{tabular}{|c|c|c|c|c|c|c|}
\hline \multirow{2}{*}{$\begin{array}{l}\text { Dietary supplements } \\
(\mathrm{n}=85)\end{array}$} & \multicolumn{6}{|c|}{ Concentration of parabens / $\left(\mathrm{ng} \mathrm{g}^{-1}\right)$} \\
\hline & $\mathrm{MeP}$ & EtP & $\operatorname{PrP}$ & $\mathrm{BuP}$ & $\mathrm{BzP}$ & $\Sigma \mathrm{PBs}$ \\
\hline GM & 59.2 & 6.12 & 11.0 & 10.1 & 60.9 & 147 \\
\hline Median & 19.2 & 4.45 & 2.54 & 8.89 & 135 & 171 \\
\hline $95^{\text {th }}$ percentile & 50881 & 66.4 & 10998 & - & - & 40209 \\
\hline Minimum & 4.39 & 2.40 & 0.56 & 7.04 & 13.6 & 27.9 \\
\hline Maximum & 120429 & 103 & 23752 & 28.5 & 283 & 144597 \\
\hline Frequency / \% & 61.2 & 71.8 & 49.4 & 21.2 & 4.7 & 89.4 \\
\hline
\end{tabular}

GM: geometric mean; MeP: methylparaben; EtP: ethylparaben; PrP: propylparaben; BuP: butylparaben; BzP: benzylparaben; $\Sigma$ PBs: sum of five parabens.

samples $(89.4 \%)$ contained at least one paraben. MeP, EtP and PrP were the most abundant compounds with mean concentrations of $19.2 \mathrm{ng} \mathrm{g}^{-1}$ (range: $4.39-120429 \mathrm{ng} \mathrm{g}^{-1}$ ), $4.45 \mathrm{ng} \mathrm{g}^{-1}$ (range: $2.40-103 \mathrm{ng} \mathrm{g}^{-1}$ ), and $2.54 \mathrm{ng} \mathrm{g}^{-1}$ (range: 0.56-23752 $\mathrm{ng} \mathrm{g}^{-1}$ ), respectively. BuP and BzP were found at low detection frequencies of 21.2 and $4.7 \%$, respectively.

Correlations among the concentrations of parabens in sports supplements were assessed by nonparametric Spearman correlation analysis. The distribution of the normality of the data was determined by a one-sample Kolmogorov-Smirnov test. Statistical significance was set at $p<0.05$. Recent studies ${ }^{7,33-37}$ have suggested a significant positive correlation between concentrations of parabens, indicating their co-applications in different consumer products, such as pharmaceuticals, food and personal care products. In line with those results, our results suggest that there were significant positive relationships between the log-transformed concentrations of MeP and EtP (correlation coefficient $(r)=0.496, p<0.01$ ) and $\log$-transformed concentrations of $\mathrm{MeP}$ and $\operatorname{PrP}(\mathrm{r}=0.767$, $p<0.001)$. However, no significant correlation was found between EtP and PrP. Thus, short chain parabens such as $\mathrm{MeP}, \mathrm{EtP}$ and PrP or mixtures of MeP/EtP or MeP/PrP are the ones most used in sports supplements.

Recently, Brazil's National Health Surveillance Agency ${ }^{52}$ has released updated guidance dietary supplement regulations. The updates were related to the authorized food additives and the conditions of their use. Moreover, dietary supplement regulation indicated a list of substances allowed to be used in food additives, as well as guidelines of use. This regulation authorizes only the use of MeP and EtP but with restrictions, such as a maximum permitted amount in preparation of food that cannot exceed $0.15 \% \mathrm{~m} / \mathrm{m}$. Although the allowed parabens were found in more than $60 \%$ of the total samples, no sample exceed the permitted value of $0.15 \%$ for $\mathrm{MeP}$ and $\mathrm{EtP}$ for their use as preservative in sports food supplements. However, it is important to highlight those parabens, not allowed by Brazilian regulation, $\mathrm{PrP}, \mathrm{BuP}$ and $\mathrm{BzP}$ were found in 49.4, 21.2 and
$4.7 \%$ of total samples. Several in vitro studies have shown that parabens are estrogenic compounds with activities in the order of $\mathrm{BzP}>\mathrm{BuP}>\mathrm{PrP}>\mathrm{EtP}>\mathrm{MeP}$. It has been suggested that parabens with longer linear side chains are more potent than those with shorter chains in vitro, and parabens with branched chains are more potent than those with linear chains. ${ }^{9,53}$ Therefore, our study suggest that Brazilians may be exposed to estrogenic not allowed parabens and their harmful effects through the intake of sports food supplements.

In pharmaceuticals, parabens are usually used as preservatives and excipients (inactive ingredients), which are added to pharmaceuticals to prevent any microbial growth and/or degradation of the drug. Moreta et al. ${ }^{37}$ analyzed 104 samples from the United States and found that liquid pharmaceuticals and solid pharmaceuticals presented the frequency of paraben occurrence of 44 and $10 \%$, respectively. The maximum concentration of total parabens found for liquid and solid pharmaceuticals were 2689 and $1.25 \mu \mathrm{g} \mathrm{g}^{-1}$, respectively. Among solid samples, dietary supplement $(n=8)$ presented the detection frequency of $25 \%$, with the median and maximum values of 0.34 and $0.53 \mu \mathrm{g} \mathrm{g}^{-1}$, respectively. Although the median concentrations found in samples in this study are lower, the frequency of detection was much higher than that observed in the dietary supplement from the United States. ${ }^{37}$ In addition to the pharmaceuticals from the United States, Moreta et al..$^{37}$ also detected similar paraben concentrations in the pharmaceutical from Spain, Italy and Japan. The detection frequency of total parabens $(>90 \%)$ in samples from China was higher than that found for other countries. ${ }^{36}$

Through the daily use of personal care products, humans are exposed to parabens mainly via the dermal absorption. The literature-reported data on detection frequencies and concentrations of parabens in personal care products and cosmetics indicate that parabens are widely used in various personal care products. The average detection frequencies based on those researches for MeP, EtP, PrP and BuP were 73, 38, 65, and 25\%, respectively. ${ }^{34,35,54,55}$ According to 
Guo and Kannan ${ }^{34}$ who evaluated the presence of parabens in 170 personal care products from United States, parabens were found in ca. $40 \%$ of rinse-off products and ca. $60 \%$ of leave-on products. The highest concentrations of MeP, EtP, PrP, and BuP were on the order of $1000 \mu \mathrm{g}$ per gram of the product. Another example is the study conducted by the same research group mentioned above, where Guo et al., ${ }^{35}$ measured concentrations of six parabens in five categories of personal care products collected from China. The authors reported that the most frequently detected parabens in personal care products from China were $\mathrm{MeP}$ and $\mathrm{PrP}$ with a detection rate of $75 \%$. The highest concentrations of $\mathrm{MeP}$ and PrP were 2,826 and 1,564 $\mu \mathrm{g} \mathrm{g}^{-1}$, respectively. Those results imply that parabens are still ubiquitous in cosmetic products.

Since parabens are authorized for use as preservatives in food, it is not surprising that many studies have reported high detection rates of parabens in various food items. Overall, the literature data indicate that different types of food items contain different levels of parabens, for example the content of parabens in processed food is higher than in non-processed foods. ${ }^{11}$ As observed in other sources, MeP, EtP and PrP are predominant in food, while BuP and $\mathrm{BzP}$ are used less frequently. The detection frequency of parabens in food is comparable to that in personal care products, but the concentrations of total and individual parabens are generally lower in food, ranging from $\mu \mathrm{g} \mathrm{g}^{-1}$ to below $n g$ g $^{-1}$ levels. ${ }^{11}$ It was described that 282 food samples from China, contained at least one of the six parabens analyzed. ${ }^{7}$ The concentrations of parabens were in the range of $0-2.53 \mu \mathrm{g} \mathrm{g}^{-1}$. The maximum concentration of MeP was $2.17 \mu \mathrm{g} \mathrm{g}^{-1}$ (vegetables) while, the maximum concentrations of EtP and PrP were 1.14 and $0.547 \mu \mathrm{g} \mathrm{g}^{-1}$, respectively (condiments). Although there was a substantial variation in the measured concentrations of parabens, there was no significant difference between the analyzed food categories. Similarly, Liao et al. ${ }^{7}$ studied the concentrations of parabens in foodstuff in the United States and the detection frequency of parabens in food was comparable level with the samples collected in China, but the concentration range was different $\left(0-0.409 \mu \mathrm{g} \mathrm{g}^{-1}\right)$ with the maximum detected concentration being ca. 6 times lower than in the samples from China. Those examples suggest that although exposure to parabens via sports supplements is lower compared to another source, it is nonetheless a way how exposure to parabens can occur and should not be ignored.

\section{Conclusions}

In conclusion, the proposed procedure for the determination of parabens in sports supplements is fast, simple, trustworthy, efficient, and sensitive. In addition, no special instrumentation is necessary to conduct the sample preparation step. These advantages, associated with the short LC-MS/MS analysis time (10 min), make the proposed method an attractive alternative for routine monitoring of parabens in numerous samples (such as control quality studies). Moreover, the occurrence and concentration of MeP, EtP, PrP, BuP, and BzP in sports supplements from Brazil were investigated. Parabens were found in almost all (89\%) sports supplements and the total concentrations varied from below LOQ to $144597 \mathrm{ng} \mathrm{g}^{-1}$. Among paraben analogs, MeP and EtP were the most frequently detected parabens that have shown a detection rate of 61.2 and $71.8 \%$, respectively. Although the MeP and EtP (permitted by the Brazilian regulation) were found in more than $60 \%$ of the total samples, no sample exceed the permitted value of $0.15 \%$ for their use as preservative in sports food supplements. However, it is also worth to mention that forbidden parabens (PrP, BuP and $\mathrm{BzP}$ ) were detected. The outcomes hereby bright the literature gap regarding the parabens exposure in sports supplements including three parabens which are prohibited in foods and these milestones will serve as a base for future studies on commercial sports supplements.

\section{Acknowledgments}

This research was supported by São Paulo Research foundation (Fundação de Amparo à Pesquisa do Estado de São Paulo-FAPESP, process number 2018/240693 , 2021/03633-0) and by the National Council of Technological and Scientific Development (CNPq). Thanks for financial support and for granting research fellowships.

\section{References}

1. Al-Jandal, N.; Saeed, T.; Azad, I.; Al-Subiai, S.; Al-Zekri, W.; Hussain, S.; Al-Hasan, E.; Ecotoxicol. Environ. Saf. 2018, 150, 280.

2. Casals-Casas, C.; Desvergne, B.; Annu. Rev. Physiol. 2011, 73, 135.

3. Mills, L. J.; Chichester, C.; Sci. Total Environ. 2005, 343, 1.

4. Vos, J. G.; Dybing, E.; Greim, H. A.; Ladefoged, O.; Lambré, C.; Tarazona, J. V.; Brandt, I.; Vethaak, A. D.; Crit. Rev. Toxicol. 2000, 30, 71 .

5. Diamanti-Kandarakis, E.; Bourguignon, J. P.; Giudice, L. C.; Hauser, R.; Prins, G. S.; Soto, A. M.; Zoeller, R. T.; Gore, A. C.; Endocr. Rev. 2009, 30, 293.

6. Giulivo, M.; Lopez de Alda, M.; Capri, E.; Barcelo, D.; Environ. Res. 2016, 151, 251.

7. Liao, C.; Liu, F.; Kannan, K.; Environ. Sci. Technol. 2013, 47, 3918. 
8. Tanabe, S.; Mar. Pollut. Bull. 2002, 45, 69.

9. Petric, Z.; Ruzić, J.; Zuntar, I.; Acta Pharm. 2021, 71, 17.

10. Haman, C.; Dauchy, X.; Rosin, C.; Munoz, J. F.; Water Res. 2015, 68,1 .

11. Wei, F.; Mortimer, M.; Cheng, H.; Sang, N.; Guo, L. H.; Sci. Total Environ. 2021, 778, 146150.

12. Ding, X. J.; Xie, N.; Zhao, S.; Wu, Y. C.; Li, J.; Wang, Z.; Food Chem. 2015, 181, 207.

13. Routledge, E. J.; Parker, J.; Odum, J.; Ashby, J.; Sumpter, J. P.; Toxicol. Appl. Pharmacol. 1998, 153, 12.

14. Soni, M. G.; Burdock, G. A.; Taylor, S. L.; Greenberg, N. A.; Food Chem. Toxicol. 2001, 39, 513.

15. Moos, R. K.; Apel, P.; Schröter-Kermani, C.; Kolossa-Gehring, M.; Brüning, T.; Koch, H. M.; J. Exposure Sci. Environ. Epidemiol. 2017, 27, 591.

16. Soni, M. G.; Carabin, I. G.; Burdockc, G. A.; Food Chem. Toxicol. 2005, 43, 985.

17. Błedzka, D.; Gromadzińska, J.; Wasowicz, W.; Environ. Int. 2014, 67, 27.

18. Byford, J. R.; Shaw, L. E.; Drew, M. G. B.; Pope, G. S.; Sauer, M. J.; Darbre, P. D.; J. Steroid Biochem. Mol. Biol. 2002, 80, 49.

19. Darbre, P. D.; Aljarrah, A.; Miller, W. R.; Coldham, N. G.; Sauer, M. J.; Pope, G. S.; J. Appl. Toxicol. 2004, 24, 5.

20. Darbre, P. D.; Byford, J. R.; Shaw, L. E.; Hall, S.; Coldham, N. G.; Pope, G. S.; Sauer, M. J.; J. Appl. Toxicol. 2003, 23, 43.

21. Darbre, P. D.; Byford, J. R.; Shaw, L. E.; Horton, R. A.; Pope, G. S.; Sauer, M. J.; J. Appl. Toxicol. 2002, 22, 219.

22. Lemini, C.; Jaimez, R.; Ávila, M. E.; Franco, Y.; Larrea, F.; Lemus, A. E.; Toxicol. Ind. Health 2003, 19, 69.

23. Anderson, F. A.; Int. J. Toxicol. 2008, 27, 1.

24. Rocha, B. A.; Bocato, M. Z.; Latorraca, E. F.; Ximenez, J. P. B.; Barbosa Jr., F.; Quim. Nova 2020, 43, 442.

25. Calafat, A. M.; Ye, X.; Wong, L. Y.; Bishop, A. M.; Needham, L. L.; Environ. Health Perspect. 2010, 118, 679.

26. Xue, J.; Wu, Q.; Sakthivel, S.; Pavithran, P. V.; Vasukutty, J. R.; Kannan, K.; Environ. Res. 2015, 137, 120.

27. Rocha, B. A.; de Oliveira, A. R. M.; Barbosa, F.; Talanta 2018 183, 94.

28. Rocha, B. A.; Asimakopoulos, A. G.; Honda, M.; da Costa, N. L.; Barbosa, R. M.; Barbosa, F.; Kannan, K.; Environ. Int. 2018, 116,269

29. Janjua, N. R.; Mortensen, G. K.; Andersson, A. M.; Kongshoj, B.; Skakkebæk, N. E.; Wulf, H. C.; Environ. Sci. Technol. 2007, 41,5564

30. Zhou, X.; Kramer, J. P.; Calafat, A. M.; Ye, X.; J. Chromatogr. B: Anal. Technol. Biomed. Life Sci. 2014, 944, 152.

31. Frederiksen, H.; Jørgensen, N.; Andersson, A. M.; J. Exposure Sci. Environ. Epidemiol. 2011, 21, 262.

32. Van Der Meer, T. P.; Artacho-Cordón, F.; Swaab, D. F.; Struik, D.; Makris, K. C.; Wolffenbuttel, B. H. R.; Frederiksen, H.; Van
Vliet-Ostaptchouk, J. V.; Int. J. Environ. Res. Public Health 2017, 14, 1059

33. Bao, J.; Wang, M.; Ning, X.; Zhou, Y.; He, Y.; Yang, J.; Gao, X.; Li, S.; Ding, Z.; Chen, B.; J. Toxicol. Environ. Health, Part A 2015, 78, 325 .

34. Guo, Y.; Kannan, K.; Environ. Sci. Technol. 2013, 47, 14442.

35. Guo, Y.; Wang, L.; Kannan, K.; Arch. Environ. Contam. Toxicol. 2014, 66, 113.

36. Ma, W. L.; Zhao, X.; Lin, Z. Y.; Mohammed, M. O. A.; Zhang, Z. F.; Liu, L. Y.; Song, W. W.; Li, Y. F.; Environ. Int. 2016, 95, 30.

37. Moreta, C.; Tena, M. T.; Kannan, K.; Environ. Res. 2015, 142 , 452.

38. European Food Safety Authority; Directive 2002/46/EC of the European Parliament and of the Council of 10 June 2002 on the Approximation of the Laws of the Member States Relating to Food Supplements, 51-57, available at https://www.fsai. ie/uploadedFiles/Consol2002_46.pdf, accessed in December 2021.

39. US Food and Drug Administration, Center for Food Safety and Applied Nutrition; Information for Consumers on Using Dietary Supplements Home Page, Center for Biologics Evaluation and Research, available at https://www.fda.gov/ food/dietary-supplements/information-consumers-usingdietary-supplements, accessed in December 2021

40. Bailey, R. L.; Gahche, J. J.; Lentino, C. V.; Dwyer, J. T.; Engel, J. S.; Thomas, P. R.; Betz, J. M.; Sempos, C. T.; Picciano, M. F.; J. Nutr. 2011, 141, 261.

41. Del Balzo, V.; Vitiello, V.; Germani, A.; Donini, L. M.; Poggiogalle, E.; Pinto, A.; PLoS One 2014, 9, e100508

42. Dwyer, J.; Nahin, R. L.; Rogers, G. T.; Barnes, P. M.; Jacques, P. M.; Sempos, C. T.; Bailey, R.; Am. J. Clin. Nutr. 2013, 97, 1331.

43. Skeie, G.; Braaten, T.; Hjartåker, A.; Lentjes, M.; Amiano, P.; Jakszyn, P.; Pala, V.; Palanca, A.; Niekerk, E. M.; Verhagen, H.; Avloniti, K.; Psaltopoulou, T.; Niravong, M.; Touvier, M.; Nimptsch, K.; Haubrock, J.; Walker, L.; Spencer, E. A.; Roswall, N.; Olsen, A.; Wallström, P.; Nilsson, S.; Casagrande, C.; Deharveng, G.; Hellström, V.; Boutron-Ruault, M. C.; Tjønneland, A.; Joensen, A. M.; Clavel-Chapelon, F.; Trichopoulou, A.; Martinez, C.; Rodríguez, L.; Frasca, G.; Sacerdote, C.; Peeters, P. H. M.; Linseisen, J.; Schienkiewitz, A.; Welch, A. A.; Manjer, J.; Ferrari, P.; Riboli, E.; Bingham, S.; Engeset, D.; Lund, E.; Slimani, N.; Eur. J. Clin. Nutr. 2009, 63, S226.

44. OCampo, D. A. B.; Molina, S. V.; Pazo, S.; Soto, J. L. P.; J. Anal. Pharm. Res. 2017, 5, DOI: 10.15406/japlr.2017.05.00126.

45. Barnes, K.; Ball, L.; Desbrow, B.; Alsharairi, N.; Ahmed, F.; Nutrition 2016, 32, 524.

46. Maughan, R. J.; J. Sports Sci. 2005, 23, 883.

47. Plotan, M.; Elliott, C. T.; Frizzell, C.; Connolly, L.; Food Chem. 2014, 159, 157. 
48. Plotan, M.; Elliott, C. T.; Oplatowska, M.; Connolly, L.; Anal. Bioanal. Chem. 2012, 403, 3057.

49. Gosetti, F.; Mazzucco, E.; Zampieri, D.; Gennaro, M. C.; J. Chromatogr. A 2010, 1217, 3929.

50. Kruve, A.; Rebane, R.; Kipper, K.; Oldekop, M. L.; Evard, H.; Herodes, K.; Ravio, P.; Leito, I.; Anal. Chim. Acta 2015, 870, 8.

51. van Nuland, M.; Rosing, H.; Schellens, J. H. M.; Beijnen, J. H.; Biomed. Chromatogr. 2020, 34, e4623.

52. Agência Nacional de Vigilância Sanitária (ANVISA); Resolução da Diretoria Colegiada (RDC) No. 239, de 26 de julho de 2018, Estabelece os Aditivos Alimentares e Coadjuvantes de Tecnologia Autorizados para Uso em Suplementos Alimentares; Diário Oficial da União (DOU), Brasília, No. 144, de 27/07/2018, p. 90, available at https://www.in.gov.br/materia/-/
asset_publisher/Kujrw0TZC2Mb/content/id/34380515/do12018-07-27-resolucao-da-diretoria-colegiada-rdc-n-239-de26-de-julho-de-2018-34380387, accessed in December 2021.

53. Fransway, A. F.; Fransway, P. J.; Belsito, D. V.; Warshaw, E. M.; Sasseville, D.; Fowler, J. F.; DeKoven, J. G.; Pratt, M. D.; Maibach, H. I.; Taylor, J. S.; Marks, J. G.; Mathias, C. G. T.; DeLeo, V. A.; Zirwas, J. M.; Zug, K. A.; Atwater, A. R.; Silverberg, J.; Reeder, M. J.; Dermatitis 2019, 30, 3.

54. Zhu, H.; Kannan, K.; Sci. Total Environ. 2020, 744, 141016.

55. Cheng, L.; Huang, K.; Cui, H.; Wang, X.; Zhang, H.; Zeng, L.; Zhang, X.; Wang, B.; Zhou, Y.; Jing, T.; Sci. Total Environ. 2020, 706, 135961. 